\title{
Study on Different Treatment Ways of Slider Joint for Solid-webbed Telescopic Jib
}

\author{
Gening $X \mathrm{U}^{1, \mathrm{a}}$, Xiaojun $\mathrm{HAN}^{1, \mathrm{~b}}$, Bin $Z \mathrm{ZO}^{2, c}$, Mingliang $\mathrm{YANG}^{1, \mathrm{~d}}$, Qing DONG ${ }^{1, \mathrm{e}}$, \\ 1Mechanical Engineering College, Taiyuan University of Science \& Technology, Taiyuan 030024, China; \\ 2Machinery Technology Development CoLtd, Beijing 100044, China \\ a Tel.: 0351-6998031,13603511650, fax: 0351-6998027 \\ a E-mail: xugening@sina.com, b E-mail: hanxiaojun116@126.com, \\ c E-mail: zuobin1981@126.com, d E-mail: sxtysunshine@163.com, e E-mail:523773587@qq.com
}

\begin{abstract}
According to greater distortion of local stress calculated in the slider joint for solid-webbed telescopic jib caused by previous simplified way, this paper puts forward to $3 \times 2$ kinds of different treatment ways: three kinds of ways dealing with fixed junction surfaces namely the coplanar way, MPC Algorithm and node coupling, two kinds of ways dealing with the corresponding sliding contact surfaces such as linear node coupling and contact nonlinear analysis. Regard the structure of solid-webbed telescopic jib with elliptical cross section as research object; analyze its feasibility and rationality of six kinds of treatment ways comparatively combining results by means of FEA software ANSYS and strength calculation theory in the overlapping and non-overlapping zones on simplification basis of the actual conditions of jib. It is found that the model's FEA results with the coplanar way in the fixed junction surfaces occur serious distortion phenomenon through the whole analysis and comparison, which the degree of distortion reaches $354.5 \%$, indicating that this treatment way has failed; The FEA results of model which sliding contact surfaces are disposed of contact nonlinear analysis are greater than the results of model which sliding contact surfaces are disposed of linear node coupling, there is no stress concentration phenomenon in this kind of treatment way, the simulation results are safer than before, and it is more consistent with the actual contact condition. Due to the contact analysis is a kind of nonlinear analysis behaviour which needs more computer resource. Therefore, the actual calculation results can be obtained more actually and economically if the node coupling is adapted to the slider joint while computer resource is nervous.
\end{abstract}

Keywords: jib, slider, distortion, node coupling, MPC Algorithm, contact analysis

\section{Introduction}

The safety and reliability of the whole structure in mobile cranes is paid more and more attention when they are becoming one of the most rapidly developed products in the present hoisting machinery industry. As the key structural parts which influence the whole safety, the jib structure's performance will directly affect the working performance of the machine. It is found that the most dangerous location of jib is mainly focused on the hinged parts between jib's derricking cylinder and the first jib or guiding and sliding joint between jib and slider. The paper [1] utilizes the beam element to model and analyze telescopic jib structure of aerial work platform, which concludes the stress and strain of the whole structure in various conditions. But there are some defects in this simplified model that it can't show stress and strain conditions of slider joints or dangerous stress of local position on jib; The papers [2,5] combine shell and solid element to model the whole jib and local solid-webbed part by cutting jib to form slider model; The paper [6] deals with the overlapping relations between slider and jib with five kinds of treatment ways on the basis of model with shell and solid element, which dealing with the fixed junction surface between each other in the coplanar way and reflecting the whole and local stress conditions of jib more completely and actually, but it still exists the local stress concentration in the coplanar position that leads to drawbacks of peak stress, resulting in serious distortion phenomenon. The paper proposes a couple of new treatment ways for the joint between slider and jib on the basis of model combining the shell and solid element and dealing with the slider joint in some kinds of treatment ways, which could analyze and verify jib model on the basis of original model's treatment ways, providing basis for safe design of jib structure.

\section{The local slider structure of jib}

The solid-webbed telescopic jib's structure of present mobile cranes is all regarding sliders up and down as the structures objects which transferring force between jibs, play a guiding and constraint role and satisfy different complex and actual engineering requirements [8]. For example, the local slider structure of jib with the form of 
box-shaped section in some company's mobile crane, as follow Fig.1, the slider in the front jib is fixed on the jib with bolt, and it is connected to the latter jib through sliding contact. The connection relation between sliders behind jib and the latter jib is similar to the former, and then realizing the guiding and transferring of force among the different jibs.

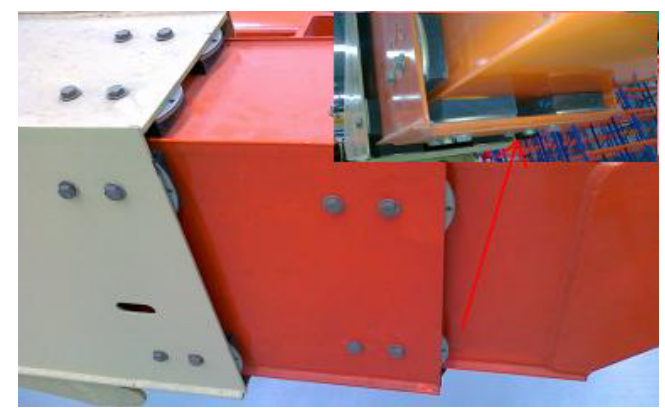

Fig.1 Real structure model of sliders in jib

\section{Theory analysis}

To analyze and calculate the whole and local structure of mobile crane's jib according to the GB/T3811-2008

"Design rules for cranes" and the literature [7], the calculation model of telescopic jib in the amplitude and rotary plane is as follow Fig. 2.
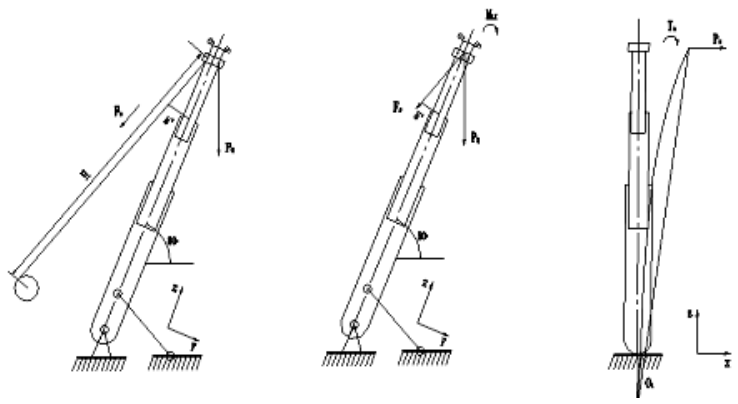

Fig.2 Calculation model of telescopic jib

The slider joint of telescopic jib is under larger concentrated force, namely the flange plate around slider will cause a larger local bending stress, resulting in unevenness of stress distribution. Therefore, not only should analyze and calculate the stress in the non-overlapping section, but also the overlapping section when calculate strength of jib structure.

1) The corner stress in $z$ point of arbitrary section in the non-overlapping positions of telescopic jib could be calculated as Eq. 1:

$$
\sigma(z)=\frac{N}{A}+\frac{M_{x}(z)}{\left(1-\frac{N}{N_{E x}}\right) W_{x}(z)}+\frac{M_{y}(z)}{\left(1-\frac{N}{N_{E y}}\right) W_{y}(z)} \leq[\sigma]
$$

Where ${ }^{N}$ is axial force of telescopic jib, $M_{x}(z) M_{y}(z)$ is basic moment to calculation section caused by the whole load of telescopic jib, $N_{E x} N_{E y}$ is critical force of telescopic jib in the amplitude and rotary plane, $A$ is sectional area of calculation section in telescopic jib and $W_{x}(z) 、 W_{y}(z)$ is section modulus of telescopic jib's calculation section to $\mathrm{X}$ and $\mathrm{Y}$ axis.
2) It is essential to acquire bearing force of guiding slider firstly when to calculate stress for overlapping zones of telescopic jib, and then get local bending stress around slider in the flange plate calculated by bearing force. Finally, get synthesis of stress combined the whole with local bending stress around slider in the flange plate, as follow Fig.3.

The bearing force of guiding slider is caused by bending moment and horizontal force of jib end. The couple of sliders which are closely next to outer jib end bear the maximum force according to analysis, and bending moment of section is $M_{x}(z)$, the horizontal force is $P_{y}$. Therefore, the bearing force of one of the sliders is as Eq. 2:

$$
F=\frac{1}{2}\left[M_{x}(\Rightarrow)+l y\right\}
$$

Where $l$ is the distance along overlapping zones of $\mathrm{jib}$ between former and latter slider.

On the basis of this, approximately calculate the local bending stress of slider around bottom- flange plate referring to formula of the board simplified to the simply supported infinite plate, as Eq. 3:

$$
\sigma_{z j}=\sigma_{\mathrm{xj}}=k \frac{3 F(1+\mu)}{4 \pi \delta_{0}^{2}} \ln \left\{\left[\frac{1-\cos \frac{\pi(x+\xi)}{b}}{1-\cos \frac{\pi(x-\xi)}{b}}\right]\left[\frac{1+\cos \frac{\pi(x-\xi)}{b}}{1+\cos \frac{\pi(x+\xi)}{b}}\right]\right\}
$$

Where $k$ is correction coefficient used for considering error between theatrical calculation and actual conditions, $k=1 / 10 \sim 1 / 20 \quad, 1 / 15$ is regularly,$\xi$ is middle position of slider, as Fig. 3, $x$ is position for calculation that mustn't be chosen in the middle position of slider, namely $x \neq \xi, \delta_{0}$ is thickness of flange plate, $b$ is distance between central lines of two plates thickness and $\mu$ is Poisson ratio of material.

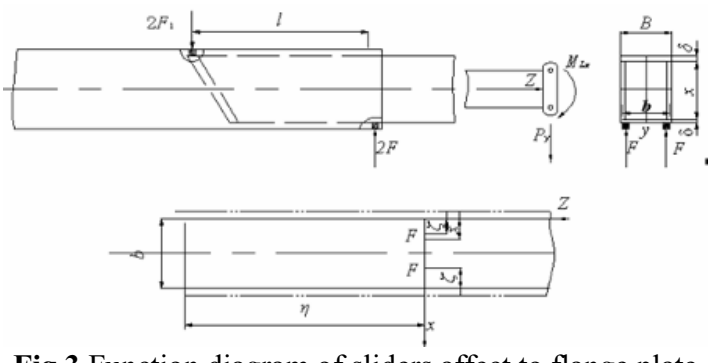

Fig.3 Function diagram of sliders affect to flange plate

The whole bending stress of jib is as Eq. 4:

$$
\sigma_{z}=\frac{M_{x}(Z)}{\left(1-\frac{N}{N_{E x}}\right) W_{x 2}}+\frac{M_{y}(Z)}{\left(1-\frac{N}{N_{E y}}\right) W_{y 2}}\left(\frac{2 x^{\prime}}{Z}\right)
$$

Therefore, the stress around slider is functioned combing with the whole and local bending stress as Eq. 5:

$$
\sigma=\sqrt{\left(\sigma_{z}+\sigma_{z j}\right)^{2}+\sigma_{x j}^{2}-\left(\sigma_{z}+\sigma_{z j}\right) \sigma_{x j}+3 \tau^{2}} \leq[\sigma]
$$

Where $\sigma_{z}$ is the whole bending stress in Z direction of calculation point of flange plate around slider, which could be calculated in nonlinear theory, $\sigma_{z j}, \sigma_{x j}$ is the local stress of flange plate around slider, $\tau$ is the shear stress of flange plate around slider and $[\sigma]$ is the 
allowable stress of steel.

The paper analyzes comparatively the error between results of FEA in every kind of treatment ways to slider joint with jib and theory calculation, evaluated by the basis of the strength theory of non-overlapping and overlapping zones, and concludes the way which is the most suitable and economic to actual condition. The detailed theoretical calculation process omits because of paper length constraints, the typical conditions and corresponding results are showed in the Table $1 \sim$ Table 3 in the chapter of the case study.

\section{The finite element analysis}

Telescopic jib is parametrically modeled in a simplified model combined with shell and solid element with help of FEA software ANSYS, and conducted a comparative study about every kind of treatment ways to overlapping slider joint between slider and jib, which is shown in Fig. 4 Fig. 5 . According to their practical overlapping condition between each other, the front slider is fixed to the outer telescopic jib and the fixed junction surfaces could be dealt with the coplanar way or generating contact pairs on the divided elements respectively. The contact pairs in the fixed junction surfaces are achieved by means of bonding contact in MPC Algorithm. The treatment ways to fixed junction surfaces between back slider and inner telescopic jib are the same with the front.

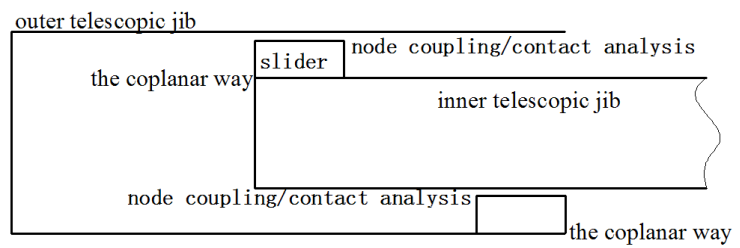

Fig.4 The coplanar way dealing with fixed junction surfaces between sliders and jib plate

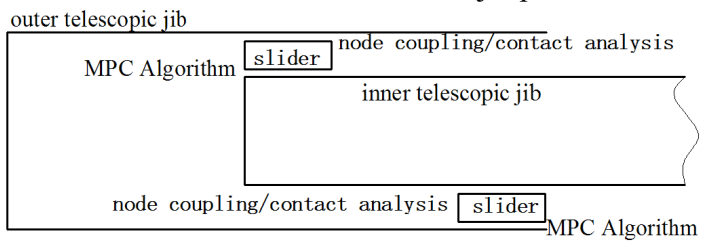

Fig.5 MPC Algorithm manner dealing with fixed junction surfaces between sliders and jib plate

MPC Algorithm [9], namely multipoint constraint equations. The nodes which are not one-to-one corresponding at the slider joint of structure are connected and the elements attached to the nodes are established contact relation between each other. The fixed junction surfaces between sliders and jib plate can be simulated by means of bonding contact which is one of the ways to achieve MPC Algorithm, and their assembly relationship also can be defined, which is equivalent to proceeding multipoint constraint algorithm with the definition of MPC multipoint constraint equations. On the basis of two treatment ways above to process nodes related to the fixed junction surfaces between slider and jib, this paper puts forward to a new treatment way, namely all the nodes on the fixed junction surfaces are to be dealt with node coupling and the translational degree of freedom (UX/UY/UZ) in all structures are to be coupled to achieve the simulation of common trends with each other. The sliding contact surface between slider and inner telescopic jib is still dealt by means of node coupling or setting structure real-time contact parameter [10,11], as is shown in Fig.6.

The local nodal coordinate system defined should also change in view of the different section forms of jib while dealing with the fixed junction surfaces or sliding contact position between sliders and jib plate by node coupling,

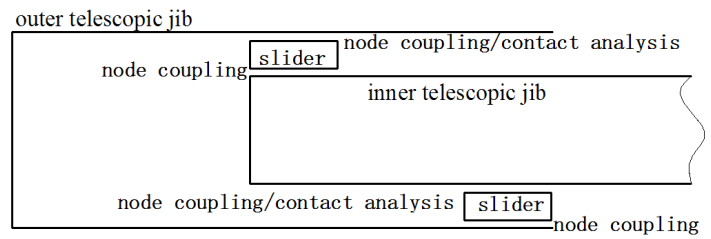

Fig.6 Node coupling way dealing with fixed junction surfaces between sliders and jib plate

the distinction between different section forms of jib must be paid more attention. For example, as for a jib with box-shaped cross-section, the translational degrees of freedom UX / UY are horizontal and vertical DOF under Cartesian Coordinate System, but the UX / UY should be transformed into DOF as radial direction of jib cross-section and the circumferential direction along cross-section of jib with elliptic or U-shaped cross-section, then the coordinate system of coupled nodes should be rotated to local coordinate system of nodes under user-defined, namely a cylindrical coordinate system. When the sliding contact position between slider and jib plate is dealt by means of node coupling, the translational degrees of freedom along jib direction in the upper sliding contact position between inner and outer jib is released, while the translational degrees of freedom in all directions are constrained in the lower sliding contact position between inner and outer jib. Concrete command streams are as follows $[12,14]$ :

! Establish a local cylindrical coordinate system, 1 is it LOCAL,11,1,XC,YC,ZC,THXY,THYZ,THZX,PAR1,P

! Select the relevant surface of model

ASEL,s,area, 15,63,48

! Choose nodes attached to the selected surface NSLA,s, 1

! Rotate coordinate system of selected nodes to activated coordinate system

NROTAT, all

! Constrain degrees of freedom along radial direction of section

CPINTF,UX,0.0001

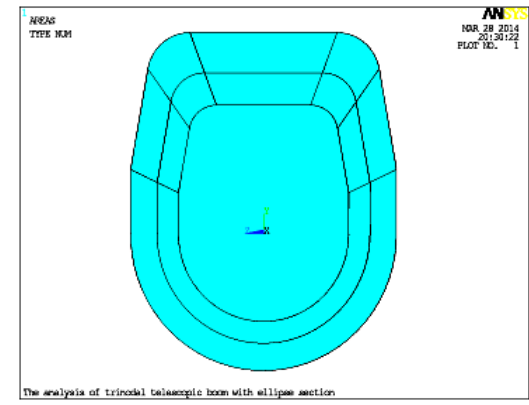

Fig.7 Cross section of jib

! Constrain degrees of freedom along circumferential 
direction of section

CPINTF, UY,0.0001

\section{Case Studies}

Take three telescopic jib for testing with elliptical cross-section of some company as study object (as Fig.7), the sectional properties could be obtained by 3D modeling software Solidworks to draw cross section of jib [8], as is shown in Table.1. The equivalent stress of the non-overlapping positions (namely the hinged parts between jib derricking cylinder and the first jib) and the overlapping positions (the slider joint between basic jib and the second jib section) is calculated based on theoretical analysis in a typical operating conditions (its maximum jib length $L=20 \mathrm{~m}$, minimum radius $R_{\min }=4.25$ $\mathrm{m}$, maximum lifting load $P_{Q}=60 \mathrm{kN}$, steel wire rope theoretical values are shown in Table.2, and the corresponding errors are in Table.3.

Some findings can be obtained from the data in Table. 2 and Table. 3 :

(1)The analysis results is obviously distorting when dealing with the fixed junction surfaces by means of the coplanar way. The local stress reaches $115 \mathrm{MPa}$ and the degree of difference with theoretical value reaches $354.5 \%$;

(2) The maximum stress of jib is similar and in line with the actual situation when dealing with the fixed junction surfaces by means of MPC Algorithm or node coupling, and when dealing with the sliding contact surfaces by using node coupling way, the maximum centralized stress is $30.4 \mathrm{MPa}$ and $30.1 \mathrm{MPa}$ respectively, which is in line with the definition of the stress concentration in Saint Venant principle;

(3) The equivalent stress (44.0MPa, 43.9MPa) with contact nonlinear analyses dealing with the sliding

Table.1: Geometric property data of jib

\begin{tabular}{|c|c|c|c|c|c|c|c|}
\hline Jib & $\begin{array}{c}\text { Length } \\
L(\mathrm{~mm})\end{array}$ & $\begin{array}{c}\text { Sectional area } \\
A\left(\mathrm{~mm}^{2}\right)\end{array}$ & $\begin{array}{c}\text { Moment of } \\
\text { inertia } \\
I_{x x}\left(\mathrm{~mm}^{4}\right)\end{array}$ & $\begin{array}{c}\text { Moment of } \\
\text { inertia } \\
I_{y y}\left(\mathrm{~mm}^{4}\right)\end{array}$ & $\begin{array}{c}\text { Radius of lower } \\
\text { flange plate } \\
R(\mathrm{~mm})\end{array}$ & \multicolumn{2}{|c|}{$\begin{array}{c}\text { Centerior of } \\
\text { section }(\mathrm{mm})\end{array}$} \\
\cline { 5 - 9 } & 7400 & $6.86 \mathrm{E}+04$ & $26.38 \mathrm{E}+09$ & $19.34 \mathrm{E}+09$ & 686.0 & $y$ & 0 \\
\hline First & 7340 & $4.39 \mathrm{E}+04$ & $10.81 \mathrm{E}+09$ & $7.92 \mathrm{E}+09$ & 548.8 & 0 & 135.9 \\
\hline Second & 7540 & $2.81 \mathrm{E}+04$ & $4.42 \mathrm{E}+09$ & $3.24 \mathrm{E}+09$ & 439.4 & 0 & 108.7 \\
\hline
\end{tabular}

Table.2: Von Mises comparative data of telescopic jib

\begin{tabular}{|c|c|c|c|c|c|c|c|c|}
\hline \multirow{2}{*}{$\begin{array}{l}\text { Checking } \\
\text { positions }\end{array}$} & \multirow{2}{*}{$\begin{array}{c}\text { Theoretical } \\
\text { calculation } \\
(\mathrm{MPa})\end{array}$} & $\begin{array}{l}\text { Treatment ways } \\
\text { for fixed junction } \\
\text { surfaces }\end{array}$ & \multicolumn{2}{|c|}{$\begin{array}{l}\text { Coplanar way } \\
\qquad(\mathrm{MPa})\end{array}$} & \multicolumn{2}{|c|}{$\begin{array}{l}\text { MPC Algorithm } \\
(\mathrm{MPa})\end{array}$} & \multicolumn{2}{|c|}{$\begin{array}{l}\text { Node coupling } \\
\qquad(\mathrm{MPa})\end{array}$} \\
\hline & & $\begin{array}{l}\text { Treatment ways } \\
\text { for sliding contact } \\
\text { surfaces }\end{array}$ & $\begin{array}{c}\text { Node } \\
\text { coupling }\end{array}$ & $\begin{array}{l}\text { Contact } \\
\text { analysis }\end{array}$ & $\begin{array}{c}\text { Node } \\
\text { coupling }\end{array}$ & $\begin{array}{l}\text { Contact } \\
\text { analysis }\end{array}$ & $\begin{array}{l}\text { Node } \\
\text { coupling }\end{array}$ & $\begin{array}{l}\text { Contact } \\
\text { analysis }\end{array}$ \\
\hline $\begin{array}{c}\text { non-overlapping } \\
\text { positions }\end{array}$ & & 14.5 & 16.2 & 17.1 & 16.8 & 18.3 & 16.1 & 18.3 \\
\hline $\begin{array}{c}\text { overlapping } \\
\text { positions }\end{array}$ & & 25.3 & 59.2 & 64.1 & 28.9 & 44.0 & 27.6 & 43.9 \\
\hline $\begin{array}{l}\text { positions with } \\
\text { maximum stress }\end{array}$ & & 25.3 & 107.0 & 115.0 & 30.4 & 44.0 & 30.1 & 43.9 \\
\hline
\end{tabular}

Table.3: The errors between different treatment ways and theoretical calculation value

\begin{tabular}{|c|c|c|c|c|c|c|}
\hline $\begin{array}{c}\text { Treatment ways for } \\
\text { the fixed junction } \\
\text { surfaces }\end{array}$ & \multicolumn{2}{|c|}{ The coplanar way (\%) } & MPC Algorithm (\%) & \multicolumn{2}{|c|}{$\begin{array}{c}\text { Node coupling } \\
(\%)\end{array}$} \\
\hline $\begin{array}{c}\text { Treatment ways for } \\
\text { the sliding contact } \\
\text { surfaces }\end{array}$ & $\begin{array}{c}\text { Node } \\
\text { coupling }\end{array}$ & $\begin{array}{c}\text { Contact } \\
\text { analysis }\end{array}$ & $\begin{array}{c}\text { Node } \\
\text { coupling }\end{array}$ & $\begin{array}{c}\text { Contact } \\
\text { analysis }\end{array}$ & $\begin{array}{c}\text { Node } \\
\text { coupling }\end{array}$ & $\begin{array}{c}\text { Contact } \\
\text { analysis }\end{array}$ \\
\hline $\begin{array}{c}\text { non-overlapping } \\
\text { positions }\end{array}$ & $11.7 \%$ & $17.9 \%$ & $15.8 \%$ & $26.2 \%$ & $11.0 \%$ & $26.2 \%$ \\
\hline overlapping positions & $134.0 \%$ & $153.4 \%$ & $14.2 \%$ & $73.9 \%$ & $9.1 \%$ & $73.5 \%$ \\
\hline $\begin{array}{c}\text { positions with } \\
\text { maximum stress }\end{array}$ & $322.9 \%$ & $354.5 \%$ & $20.2 \%$ & $73.9 \%$ & $18.9 \%$ & $73.5 \%$ \\
\hline
\end{tabular}

force $F_{S}=30 \mathrm{kN}$, amplitude angle is $80^{\circ}$, as is shown in Fig.2). The jib's finite element models were established respectively dealing with six treatment ways about the joint between slider and jib by ANSYS. The finite element equivalent stress of models is obtained after getting them analyzed, the comparative results with contact surfaces is greater than those dealing with linear nodes coupling way $(30.4 \mathrm{MPa}, 30.1 \mathrm{MPa})$. This is due to setting real-time contact pair parameters while making contact analysis and considering the friction between each other, which cause the jib equivalent stress is larger and the analysis result tends to be safer. 
The contour plots of finite element models with all kinds of treatment ways are shown in Fig. $8 \sim$ Fig. 10 respectively:

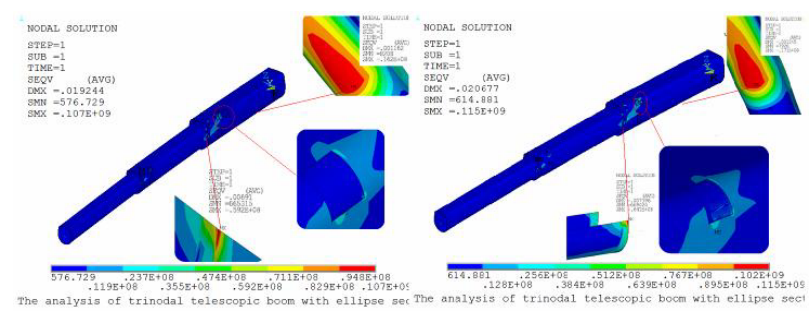

Fig.8 Coplanar + Linear node coupling/Contact nonlinear

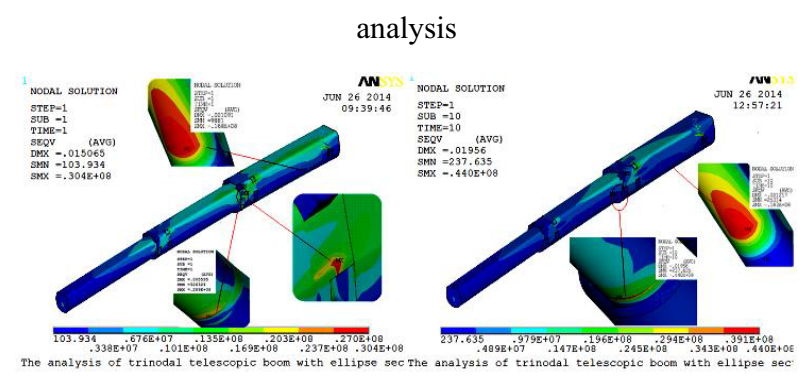

Fig.9 MPC Algorithm +Linear node coupling/Contact nonlinear

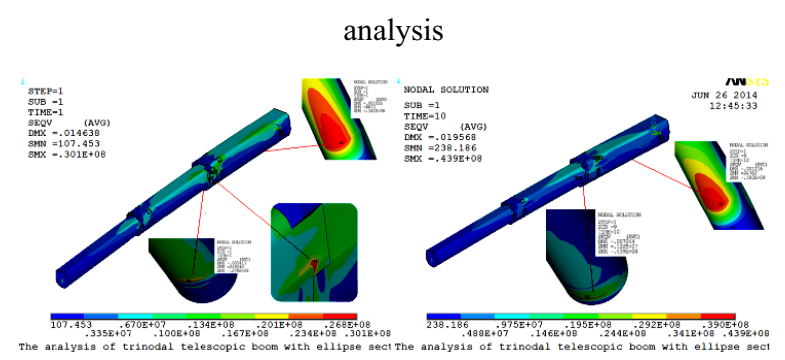

Fig.10 Node coupling +Linear node coupling/Contact nonlinear analysis

As Fig.8 shows, the analysis results occur stress distortion when the fixed junction surfaces are dealt with the coplanar way in the first jib where latter sliders of inner second telescopic jib are contacted with, whatever the nodes between the contact surface are coupled linearly or contacted analysis non-linearly, which is seriously inconsistent with the theoretical values and the actual stress conditions.

Fig.9 and Fig.10 show that the results occur a small range of stress concentration when dealing the fixed junction surfaces with MPC Algorithm or node coupling and dealing the sliding contact surfaces with node coupling between slider and jib, which occur in the overlapping position where the sharp slider of first jib and the second jib, and the errors between two treatment ways are less than $1 \%$; The jib don't occur stress concentration phenomenon when the contact surfaces are dealt with contact nonlinear analysis, and there is no cusp stress, the location with maximum stress occurs on the second jib contacted with the low slider connected with the basic jib, finally the stress is gradually extended from the position of the jib evenly throughout the whole second jib, which is in consistent with the actual stress condition.

\section{Conclusions}

A) Compared to the coplanar way, the analytical results obtained from MPC Algorithm and node coupling dealing with the fixed junction surfaces are more realistic, the distortion degree of stress concentration is also much lower than before, which is reduced by $73.6 \%$.

B) Compared to the linear node coupling treatment way in dealing with the sliding contact surfaces, contact nonlinear analysis treatment way is more truly reflected to its contact boundary, which simulates the actual working conditions more accurately, and there are no stress concentration zones. The maximum stress positions all occur in the second jib where it contacts with the first $\mathrm{jib}$ and the analytical results are more credible when objecting to the concrete situation.

C) In an environment which computational resource is far from enough, dealing the slider joints with node coupling will greatly save more computational resource, which changes nonlinear analysis into linear analysis, it is more convenient than setting the relevant parameters of contact pairs and the results are in according to the actual situation.

\section{Acknowledgements}

This paper is supported by National Hi-tech Research and Development Program of China ( 863 Program, Grant No. 2013AA040203) This paper is supported by National Hi-tech Research and Development Program of China (863 Program, Grant No. 2013AA040203) and College Students' Innovative Project of Taiyuan University of Science and Technology (UIT Project, Grant No. XJ2010009)

\section{References}

1. Qing-mei Lu. Study of comparative analysis on different specified model of aerial work platform [D]. Dalian: Dalian University of Technology, (2012).

2. Ai-min Ji, Duo Peng, Mu-nan Liu, et al. Finite element analysis of telescopic jib on model QY25K truck crane $[\mathrm{J}]$. Construction Machinery and Equipment, Vol. 34, Issue 1, (2003), pp.19 21.

3. Ai-min Ji, Pei-qiang Zhang, Duo Peng, et al. Finite element analysis for local stability of telescopic boom of truck crane [J]. Agricultural Engineering Journal,Vol.35,Issue6,( 2004), pp.48 51.

4. Ru-min Teng, Kan-yuan Liu, Li Chen. FEM calculation for hoisting performance of large-tonnage telescopic boom cranes $[\mathrm{J}]$. Chinese journal of construction machinery, Vol. 9, Issue 2, (2011), pp.194 199.

5. Feng-yi Lu, Jin-jin Gao, Rui-gang Yang, Ge-ning $\mathrm{Xu}$. Research on stochastic finite element reliability analyses method of the structure for the truck crane boom [J]. Applied mechanics and mechanical engineering vols, (2013), pp. 589 595.

6. Xue Lin. Analysis of contact problems and study of regularity on telescopic jib's sliders [D]. Dalian: Dalian University of Technology, (2008).

7. Ge-ning $\mathrm{Xu}$. Mechanical equipment and metal 
structure Design. (2th ed) [M]. Beijing: China Machine Press, (2009).

8. Zhi-min Li. Stress analysis of the sliding blocks on the telescopic jib and the research of its character [D]. Chengdou: Southwest Jiaotong Un1versity, (2009).

9. Yuan-fang Tao, Jia-qing You, Chun-yan Jia. The trolley mechanism of bridge crane loading mode based on Ansys [J]. Hoisting and conveying machinery, (2014)(3), pp. 67 70.

10. Campos L T, Oden JTK. A Numerical analysis of class of contact problem with friction in electrostatics $[\mathrm{J}]$.Computer Meth and engine,(1982)(34), pp. 824-844.

11. M Abid. et al. A parametric study of metal-to-metal contact flanges with optimized geometry for safe stress and no-leak conditions $[\mathrm{J}]$. International journal of pressure vessels and piping, (2004)(81), pp. 69 73.

12. Pan Zeng, Li-ping Lei, Gang Fang. Finite Element Analysis Guide: Modeling and Analysis of Structure China Machinery Press [M], Beijing: China Machine Press, (2010).

13. Xin-min Wang. ANSYS Gong Cheng Jie Gou Fen $\mathrm{Xi}$ [M], Beijing: China Communications Press, (2007).

14. .Shu-guang Gong, Gui-lan Xie, Yun-qing Huang. ANSYS Parametric Design Language Guide [M], Beijing: China Machinery Press, (2009). 